\title{
A qualitative study of online information-seeking preferences among cancer survivors
}

\author{
Alexandra Budenz ${ }^{1}$ - Alix G. Sleight ${ }^{2} \cdot$ William M. P. Klein ${ }^{3}$
}

Received: 23 November 2020 / Accepted: 1 July 2021 / Published online: 9 September 2021

This is a U.S. government work and not under copyright protection in the U.S.; foreign copyright protection may apply 2021

\begin{abstract}
Purpose As the cancer survivor population increases, diminished health care provider capacity will place more responsibility on survivors to obtain health information. Many survivors search for cancer information online, yet there is a dearth of research on how survivors obtain and engage with this information. This study examined cancer survivors' informationseeking behaviors and perceptions during a self-guided online search task.

Methods Ten adult cancer survivors (largely breast and thyroid) completed a task in which they searched for online cancerrelated information of their choice. Participants were asked to verbally narrate the procedural aspects of the task and provide real-time responses to the search results and experiences related to the task. Transcripts were analyzed using a qualitative descriptive approach, and codes and themes were examined and interpreted.

Results Participants searched primarily for information specific to their cancer type and stage, seeking personalized information about risk factors, prognosis, and treatments. Additionally, participants reported having to engage in excessive navigation to find relevant cancer information, citing aesthetic, usability, and credibility features of the websites that they considered barriers to obtaining this information.

Conclusions Survivors' online health information needs require streamlined cancer information resources that are disaggregated by cancer type, stage, and treatment course and located on websites with aesthetic and usability features that facilitate expedient searches for personally relevant cancer information.

Implications for Cancer Survivors This study provides useful perspectives of cancer survivors that may inform the development of online cancer resources to better serve this population.
\end{abstract}

Keywords Cancer $\cdot$ Survivor $\cdot$ Stage

Alexandra Budenz

Alexandra.budenz@nih.gov

1 Tobacco Control Research Branch, Behavioral Research Program, Division of Cancer Control and Population Sciences, National Cancer Institute, 9609 Medical Center Dr, Rockville, MD 20850, USA

2 Department of Physical Medicine and Rehabilitation, Cedars-Sinai, 8700 Beverly Blvd., NT 7217, Los Angeles, CA 90048 , USA

3 Office of the Associate Director, Behavioral Research Program, Division of Cancer Control and Population Sciences, National Cancer Institute, 9609 Medical Center Dr, Rockville, MD 20850, USA

\section{Background}

Cancer survivorship has been described as a continuum of evolving needs spanning from cancer diagnosis to the end of life [1,2]. There are approximately 17 million cancer survivors in the USA, and, by 2030, that number is expected to grow to 22 million [3]. As the number of cancer survivors increases, the current health care model will no longer have the capacity to adequately support cancer survivors' needs [4]. Some of the responsibilities of obtaining health information and managing symptoms will be increasingly shifted from health care professionals to cancer survivors themselves [5]. Cancer survivors experience many needs throughout their cancer journey, including obtaining adequate information about available treatments, managing concerns after treatment, and getting assistance with health care decision-making [6]. The growing availability of health information may empower cancer survivors 
to have more autonomy over their health care experiences [7], yet many cancer survivors still report a variety of unmet health information needs [8, 9]. Moreover, the tendency for research to focus on specific and common cancer types (e.g., breast or prostate) limits the understanding of health information needs in the wider population of cancer survivors [10-12].

Pervasive use of the internet and digital technologies (e.g., smartphones, tablets) has increased the availability and accessibility of online health information. Approximately $90 \%$ of adults in the USA use the internet, and internet use is growing across demographic groups [13]. Furthermore, $81 \%$ of the US adult population owns a smartphone, and approximately $75 \%$ own desktop or laptop computers [13]. A recent study analyzing ten cycles of the Health Information National Trends Survey (2008-2017) found that, across all survey years, an average of $69 \%$ of participants started their health information searches online [14]. Notably, cancer is one of the most frequently searched health topics online [15].

Many cancer survivors are engaged with or interested in engaging with online health information resources [16-18], and cancer survivors rank the internet as second only to health care providers as a preferred source of health information $[19,20]$. One study showed that cancer survivors who seek online health information report feeling more prepared for cancer treatment and able to advocate for their needs in health care encounters [17]. A limited number of studies have assessed cancer survivors' online information seeking habits, including attitudes towards online health information seeking and desired online health information content [17, 20, 21]. However, to our knowledge, no studies to date have used computer search tasks to study real-time and naturalistic online cancer information seeking in cancer survivors. A small number of studies have used internet search tasks to examine online health information seeking behaviors [22-24], but most of these studies have required participants to engage in prescribed search tasks, rather than participant-driven searches, and none of the aforementioned studies was specifically focused on cancer survivors.

This study sought to explore (1) behavioral patterns of online cancer information seeking in a small sample of cancer survivors through an intensive self-guided, open-ended computer search task; (2) cancer survivors' perceptions about the results of their online cancer information searches; and (3) cancer survivors' process of evaluating online cancer information.

\section{Methods}

\section{Recruitment and enrollment}

This study was one component of a parent qualitative study of online cancer information needs, preferences, and behaviors of cancer survivors. Adult cancer survivors aged 18 and older who reported seeking health information online following their cancer diagnosis were recruited from the Washington DC, MD, and Virginia metropolitan area. To be eligible to participate, cancer survivors were required to be between the active treatment phase (i.e., still receiving cancer treatment at the time of the study) and 24 months following completion of their primary cancer treatment to ensure, for the purposes of the parent study, that participants could recall their online cancer information seeking behaviors.

Participants were recruited by UserWorks, a user experience design and usability firm located in Maryland [25]. UserWorks has a proprietary database of registered cancer survivors from the DC, MD, and Virginia metropolitan area from which to recruit participants for cancer-related studies. Participants in the database were contacted by UserWorks, and interested participants were screened for inclusion criteria. Eligible participants were asked to provide verbal informed consent by phone and were subsequently recruited to the study. This study was approved by the National Institutes of Health Institutional Review Board.

\section{Search task}

Data for this study were collected between December 2019 and January 2020. Participants were asked to conduct an open-ended search task, in which they were asked to use the Google search engine to search for cancer information of their choice in the way that they would at home. They were then asked to choose websites from the search results that they wished to navigate for further examination. In order to create an environment that was closest to at-home searching, participants were asked to use a think-aloud approach during their searches, verbally narrating their actions and responses in real time $[22,26]$. Participants were instructed to provide verbal narration of the procedural aspects of the task and real-time verbal responses to the results of their search and overall experiences with the search task. The researchers also asked probing questions about participants' searches related to their decisions to choose certain websites, their general impressions of the websites, their perceived trustworthiness of the information on the websites, and how they might use the information they found on the websites outside of the study setting. The researchers allowed participant feedback to guide further probing questions. The search task sessions lasted $30 \mathrm{~min}$ on average, and participant narration and feedback were audio recorded. Participants were compensated $\$ 75$ for participating in the study. Notably, these data were collected prior to the COVID-19 pandemic's spread in the USA, and therefore, search results were not influenced by interest in COVID-19-related topics. 


\section{Data analysis}

Participant recordings were transcribed verbatim for analysis. Although audio recordings were revisited throughout the interview process to inform future interviews, the formal data analysis took place after all of the data were collected and all recordings were transcribed. Transcripts were analyzed using a qualitative descriptive approach, which focuses on summarizing the lived experiences of participants through active engagement with qualitative data in a manner that relies heavily on the data to inform study conclusions [27]. Specifically, we utilized the techniques of coding and thematic analysis, in which the researchers ascribe "codes" or labels to salient parts of the transcript text, actively process patterns across codes, and organize codes into larger themes representing meaningful categories [28]. Two of the authors (AS and $\mathrm{AB}$ ) simultaneously coded two transcripts to establish a codebook, conducting repeated readings of the transcripts while making detailed analytic memos [28]. AS and $\mathrm{AB}$ subsequently compared transcripts and discussed the codes and content area discrepancies that arose until consensus on a codebook was reached. $\mathrm{AS}$ and $\mathrm{AB}$ then divided the remaining transcripts to be coded using the established codebook. Each of the two authors was designated as the primary coder for their remaining transcripts, while the other researcher acted as a secondary coder who reviewed the primary analyst's transcripts for completeness and accuracy. Any discrepancies or changes to the coding scheme were discussed, and all transcripts were updated to reflect any changes made throughout the content analysis process. After all transcripts were analyzed and codes were established, the researchers discussed the findings and extrapolated groups of codes into larger content areas for interpretation. Themes were largely data-driven but also informed by the study aims $[27,28]$.

\section{Results}

\section{Sample characteristics}

A total of 10 cancer survivors from the DC, MD, and Virginia metropolitan region participated in the study, and $60 \%$ were diagnosed with breast cancer, $20 \%$ were diagnosed with thyroid cancer, and the remaining participants were diagnosed with lung, brain, liposarcoma, or stomach cancers ( $10 \%$ of sample for each remaining cancer type). Twenty percent of participants reported being diagnosed with multiple cancer types. Forty percent of participants were in active cancer treatment, $10 \%$ were 1-6 months postprimary treatment, $30 \%$ were $7-12$ months post-primary treatment, and 20\% were 13-24 months post-primary treatment. Ninety percent of the sample identified as female, $50 \%$ of the sample identified as Black/African American (40\% identified as White), and 60\% were between the ages of 41 and 60 . Half of the sample had a degree from a 4-year college, and 20\% were high school graduates. Most participants (70\%) reported that they spent between two and $5 \mathrm{~h}$ per week searching for health information online, and most reported searching for this information on a smartphone $(90 \%)$ or a laptop (70\%). Over half of participants (60\%) also reported that they searched for health information online several times a week after being diagnosed with cancer. Sample characteristics are shown in Table 1.

\section{Overview of content areas}

The overarching content areas that arose from the analysis were (1) types of sources chosen, (2) search topics, (3) factors influencing online information preferences/website selection, (4) sentiments about information found in searches, (5) sentiments about aesthetics and usability features of chosen websites, and (6) planned actions to take with search information. Types of sources chosen refer to the types of websites to which participants navigated during the search task. Search topics were defined as the subjects for which participants initially searched on the search engine and subsequent topics that participants explored in more depth following their initial searches. Factors influencing online information preferences/website selection were defined as participant explanations of their reasoning for choosing certain websites during the search task. Sentiments about information found in searches were defined as participant reports about their experiences managing and processing the information resulting from their searches. Sentiments about aesthetics/features were defined as user responses to the visual and usability aspects of their chosen websites. Finally, planned actions referred to participant reports of how they might use the search information outside of the study setting. Definitions of content areas, themes, and examples of participant reports within each theme are shown in Table 2.

\section{Types of sources chosen}

The most commonly chosen sources during the search tasks were non-profit websites $(\mathrm{n}=5$ participants $)$ and US government websites $(n=4)$. Four participants also visited cancer center/health care facility/hospital websites. Three participants chose news websites, two of which were health news websites as opposed to general news websites. Participants were not limited to one source, and four participants navigated to multiple websites. Notably, four participants initially navigated to the "people also ask" function on the first Google search results page. This function lists other commonly searched questions related 
Table 1 Sample demographics of cancer survivor participants $(\mathrm{N}=10)$

\begin{tabular}{|c|c|c|}
\hline & $\mathrm{N}$ & $\%$ \\
\hline \multicolumn{3}{|l|}{ Age range } \\
\hline $31-40$ & 2 & 20.0 \\
\hline $41-50$ & 3 & 30.0 \\
\hline $51-60$ & 3 & 30.0 \\
\hline $60+$ & 2 & 20.0 \\
\hline \multicolumn{3}{|l|}{ Type of cancer (not mutually exclusive) } \\
\hline Breast & 6 & 60.0 \\
\hline Thyroid & 2 & 20.0 \\
\hline Lung & 1 & 10.0 \\
\hline Brain & 1 & 10.0 \\
\hline Liposarcoma & 1 & 10.0 \\
\hline Stomach & 1 & 10.0 \\
\hline \multicolumn{3}{|l|}{ Stage of primary cancer treatment/post-treatment } \\
\hline In active treatment & 4 & 40.0 \\
\hline $1-6$ months post primary treatment & 1 & 10.0 \\
\hline $7-12$ months post primary treatment & 3 & 30.0 \\
\hline $13-24$ months post primary treatment & 2 & 20.0 \\
\hline \multicolumn{3}{|l|}{ Gender identity } \\
\hline Male & 1 & 10.0 \\
\hline Female & 9 & 90.0 \\
\hline \multicolumn{3}{|l|}{ Race } \\
\hline White & 4 & 40.0 \\
\hline Black/African American & 5 & 50.0 \\
\hline Asian & 1 & 10.0 \\
\hline Ethnicity- Hispanic/Latino/of Spanish origin & 1 & 10.0 \\
\hline \multicolumn{3}{|l|}{ Highest level of education } \\
\hline High school graduate & 2 & 20.0 \\
\hline Some college & 1 & 10.0 \\
\hline 2-year associate degree & 1 & 10.0 \\
\hline 4-year college & 5 & 50.0 \\
\hline Graduate degree & 1 & 10.0 \\
\hline \multicolumn{3}{|c|}{ Time spent online searching for health information weekly } \\
\hline Between 2 and $5 \mathrm{~h} /$ week & 7 & 70.0 \\
\hline Over $5 \mathrm{~h} /$ week & 3 & 30.0 \\
\hline \multicolumn{3}{|c|}{ Time spent online searching for health information after cancer diagnosis and during treatment } \\
\hline A few times & 2 & 20.0 \\
\hline Several times a week & 6 & 60.0 \\
\hline Several times a month & 2 & 20.0 \\
\hline \multicolumn{3}{|c|}{ Devices used to search for health information online (not mutually exclusive) } \\
\hline Laptop & 7 & 70.0 \\
\hline Smartphone & 9 & 90.0 \\
\hline Desktop & 3 & 30.0 \\
\hline Tablet & 2 & 20.0 \\
\hline
\end{tabular}

to the topic searched and contains drop-down menus with suggested links to websites that purportedly address those questions. Three of those four participants navigated to a website suggested in the "people also ask" box.

\section{Search topics}

Although participants generally began their search engine query with one search topic, many of these initial searches 
Table 2 Findings of content analysis-overarching content areas and subthemes

\begin{tabular}{|c|c|c|c|}
\hline Content area and themes & Definition & Example subthemes & $\begin{array}{l}\mathrm{n} \text { reporting } \\
\text { theme }\end{array}$ \\
\hline Types of sources & Websites accessed during search task & - & - \\
\hline Non-profit & $\begin{array}{l}\text { Website belonging to a non-profit organiza- } \\
\text { tion }\end{array}$ & $\begin{array}{l}\text { - American Cancer Society } \\
\text { - Breastcancer.org }\end{array}$ & 5 \\
\hline US government & $\begin{array}{l}\text { Website belonging to a US federal govern- } \\
\text { ment agency }\end{array}$ & $\begin{array}{l}\text { - National Institutes of Health } \\
\text { - National Cancer Institute }\end{array}$ & 4 \\
\hline Cancer center/health care facility/hospital & $\begin{array}{l}\text { Website belonging to a health care organi- } \\
\text { zation }\end{array}$ & $\begin{array}{l}\text { - Sloan Kettering } \\
\text { - Mayo Clinic }\end{array}$ & 4 \\
\hline News & Website belonging to a news organization & $\begin{array}{l}\text { - Forbes } \\
\text { - Medical News Today }\end{array}$ & 3 \\
\hline Search topics & Subjects searched during search tasks & - & - \\
\hline Specific to participant cancer type & $\begin{array}{l}\text { Information related to participants' specific } \\
\text { cancer type rather than general cancer } \\
\text { information }\end{array}$ & $\begin{array}{l}\text { - Differences between cancer subtypes } \\
\text { - Symptoms }\end{array}$ & 6 \\
\hline What to expect during cancer journey & $\begin{array}{l}\text { What participant should expect to experi- } \\
\text { ence during their cancer and treatment } \\
\text { experiences }\end{array}$ & $\begin{array}{l}\text { - Treatment side effects } \\
\text { - What to expect at each cancer stage }\end{array}$ & 6 \\
\hline Prognosis/mortality statistics/survival rates & $\begin{array}{l}\text { Anticipated prognosis of people with par- } \\
\text { ticipants' cancer type }\end{array}$ & $\begin{array}{l}\text { - Survival rates } \\
\text { - Mortality statistics }\end{array}$ & 4 \\
\hline Cancer/cancer risk factors & $\begin{array}{l}\text { Factors that cause or increase risk for } \\
\text { cancer }\end{array}$ & $\begin{array}{l}\text { - Lifestyle } \\
\text { - Genetic }\end{array}$ & 3 \\
\hline Available treatments & $\begin{array}{l}\text { Types of treatments available for partici- } \\
\text { pants' cancer type }\end{array}$ & $\begin{array}{l}\text { - Types of procedures } \\
\text { - Outcomes of treatment }\end{array}$ & 3 \\
\hline News about cancer & $\begin{array}{l}\text { News stories or press releases related to } \\
\text { participants' cancer type }\end{array}$ & $\begin{array}{l}\text { - New scientific research results } \\
\text { - Upcoming clinical trials }\end{array}$ & 2 \\
\hline Lifestyle factors/health behaviors & $\begin{array}{l}\text { Lifestyle factors/health behaviors that can } \\
\text { help to manage the effects of cancer and } \\
\text { cancer treatment }\end{array}$ & $\begin{array}{l}\text { - Diet } \\
\text { - Physical activity }\end{array}$ & 2 \\
\hline Cancer recurrence & $\begin{array}{l}\text { Risk of cancer returning or risk of second } \\
\text { cancers }\end{array}$ & $\begin{array}{l}\text { - Likelihood of recurrence/second } \\
\text { cancers } \\
\text { - Treatments for second cancers }\end{array}$ & 2 \\
\hline $\begin{array}{l}\text { Factors influencing information prefer- } \\
\text { ences/website selection }\end{array}$ & $\begin{array}{l}\text { Participant reasoning for choosing certain } \\
\text { websites during search task }\end{array}$ & - & - \\
\hline Trustworthiness & $\begin{array}{l}\text { Extent to which participant perceptions of } \\
\text { how trustworthy a website was influenced } \\
\text { their decision to navigate to or disregard } \\
\text { a website }\end{array}$ & $\begin{array}{l}\text { - Well-known/familiar organization } \\
\text { - References to scientific sources }\end{array}$ & 8 \\
\hline Position in search engine results & $\begin{array}{l}\text { Extent to which the websites' serial posi- } \\
\text { tioning in the search results influenced } \\
\text { participant decisions to navigate to or } \\
\text { disregard a website }\end{array}$ & $\begin{array}{l}\text { - Payed placement } \\
\text { - Choosing first results }\end{array}$ & 4 \\
\hline Patient-centeredness of website & $\begin{array}{l}\text { Extent to which the website's congru- } \\
\text { ency to participants' cancer experience } \\
\text { influenced their decision to navigate to or } \\
\text { disregard a website }\end{array}$ & $\begin{array}{l}\text { - Specific to their cancer type } \\
\text { - Consistent with their experiences } \\
\text { with cancer/cancer treatment }\end{array}$ & 3 \\
\hline Sentiments about information found & $\begin{array}{l}\text { Participant experiences managing/process- } \\
\text { ing search information }\end{array}$ & - & - \\
\hline Excessive navigation & $\begin{array}{l}\text { Participant reported that their chosen web- } \\
\text { sites required too much navigation to find } \\
\text { relevant information }\end{array}$ & $\begin{array}{l}\text { - Time spent on site finding informa- } \\
\text { tion } \\
\text { - Number of clicks }\end{array}$ & 5 \\
\hline Up to date information & $\begin{array}{l}\text { Participant reported a preference for the } \\
\text { most up to date cancer information }\end{array}$ & $\begin{array}{l}\text { - Marking sources with publication } \\
\text { dates } \\
\text { - Criteria for up to date information }\end{array}$ & 3 \\
\hline High volume of information & $\begin{array}{l}\text { Participant reported that search results } \\
\text { yielded too high of a volume of informa- } \\
\text { tion or links }\end{array}$ & $\begin{array}{l}\text { - Number of websites listed in search } \\
\text { results } \\
\text { - Time required to find the right source }\end{array}$ & 3 \\
\hline
\end{tabular}


Table 2 (continued)

\begin{tabular}{|c|c|c|c|}
\hline Content area and themes & Definition & Example subthemes & $\begin{array}{l}\mathrm{n} \text { reporting } \\
\text { theme }\end{array}$ \\
\hline Anxiety & $\begin{array}{l}\text { Participant reported that the information } \\
\text { found had implications for fear/anxiety } \\
\text { surrounding their cancer }\end{array}$ & $\begin{array}{l}\text { - Elicited anxiety } \\
\text { - Reduced anxiety }\end{array}$ & 2 \\
\hline Sentiments about website aesthetics & $\begin{array}{l}\text { Participant responses to the visual and } \\
\text { usability aspects of their chosen websites }\end{array}$ & - & - \\
\hline Fonts & Sentiments towards fonts used on website & $\begin{array}{l}\text { - Size } \\
\text { - Bolding fonts }\end{array}$ & 4 \\
\hline Pictures & Sentiments towards pictures on website & $\begin{array}{l}\text { - Size } \\
\text { - Content }\end{array}$ & 4 \\
\hline Text/readability & $\begin{array}{l}\text { Sentiments towards text portions of the } \\
\text { website that require reading }\end{array}$ & $\begin{array}{l}\text { - Breaking down information } \\
\text { - Time spent reading }\end{array}$ & 3 \\
\hline Website colors & $\begin{array}{l}\text { Sentiments towards colors used in website } \\
\text { design }\end{array}$ & $\begin{array}{l}\text { - Contrast } \\
\text { - Colorful }\end{array}$ & 3 \\
\hline Useful website features & $\begin{array}{l}\text { Participant reports of website features they } \\
\text { perceived as useful }\end{array}$ & $\begin{array}{l}\text { - Live chat } \\
\text { - Blog/forum }\end{array}$ & 5 \\
\hline Planned actions & $\begin{array}{l}\text { How participant might use search informa- } \\
\text { tion outside of the study setting }\end{array}$ & - & - \\
\hline Sharing with friends/family/other survivors & $\begin{array}{l}\text { Participant reported willingness to share } \\
\text { information found during search task with } \\
\text { friends/family/other cancer survivors }\end{array}$ & $\begin{array}{l}\text { - Helping to educate other survivors } \\
\text { - Answering family's questions about } \\
\text { cancer }\end{array}$ & 4 \\
\hline Sharing with health care provider & $\begin{array}{l}\text { Participant reported willingness to share } \\
\text { information found during search task with } \\
\text { health care provider }\end{array}$ & $\begin{array}{l}\text { - Validating information } \\
\text { - Comparing health care provider rec- } \\
\text { ommendations to online information }\end{array}$ & 3 \\
\hline
\end{tabular}

were followed by subsequent searches related to their chosen topic.

\section{Information about specific cancer type}

Information specific to the participant's cancer type $(n=6$ participants chose this topic) was one of the most common topics searched. Five of these six participants began their search with topics specific to their type of cancer, rather than general cancer information, and one of these participants began searching for general cancer information and eventually navigated to information specific to her cancer type. Some participants simply searched for their type of cancer in particular, but some subtopics within these searches included information about the organ affected by cancer ( $n=1$ participant), differences between subtypes of their cancer $(n=1)$, symptoms of their cancer type $(n=1)$, and incidence of their cancer type $(n=1)$. One participant reported that he searched for symptoms of his cancer to allay fears about re-experiencing cancer symptoms:

“I would probably go to 'symptoms' [on chosen website] just mainly because I was a victim of undergoing this...I can look for moments of 'Praise God!' of [cancer] not being dispersed amongst myself again."

\section{[Participant 10, stomach cancer]}

\section{What to expect during the cancer journey}

Participants also commonly searched for what to expect during the cancer journey $(n=6)$. The most common search within this larger topic was cancer treatment side effects ( $n=3$ participants), which included joint pain during chemotherapy, hair loss as a result of cancer treatment, and interactions between cancer treatments and other medications. Other searches within this topic included what to expect at each cancer stage $(n=2)$ and lifestyle changes following cancer diagnosis $(n=1)$.

\section{Other search topics}

Participants also commonly searched for prognosis of their cancer types $(n=4)$. Other common searches were cancer risk/risk factors $(n=3)$ and available treatments for participants' cancer types $(n=3)$. Less common search topics included news related to participants' cancer types $(n=2)$, lifestyle factors/health behaviors to manage the effects of cancer and cancer treatment $(n=2)$, and cancer recurrence $(n=2)$. 


\section{Factors influencing information preferences/ website selection}

\section{Trustworthiness of source}

Trustworthiness was the most commonly reported factor in choosing information sources during the search task $(n=8)$. Two participants also reported that they were more likely to choose and trust a website if the organization was well known or familiar to them. Some participants reported that, if the website contained references to research articles or grant support documentation, they perceived the website to be more trustworthy $(n=2)$. One participant described the actions that she would take to validate the information she found on her chosen website:

"I take the information that they provided on this website... and I see, 'is there any... journal articles that back this folk wisdom?'... the problem with a lot of websites...is you go to a website or even a journal, even a popular article...or some crunchyroll or nature website...And they'll refer to an article that might even be scholarly. But they failed to put the reference at the bottom." [Participant 8, breast and thyroid cancer]

Participants who reported being concerned about trustworthiness also mentioned some aspects of the websites they chose that reduced their perception of the website's trustworthiness. Three participants reported that seeing advertisements on their chosen websites reduced their feelings of trust towards the website. Two participants reported that they were less likely to trust the website if they believed that the organization was commercial rather than informational, or if the organization was perceived to have corporate entanglements. One participant described limitations to her perceived trustworthiness of a cancer center/health care facility/ hospital website:

"I would say [I trust this source] $98 \%$ of the time... there was a big scandal some time ago...the president or somebody that was important...had money put into drug companies. So, I take it with a $98 \%$ accuracy... that's just how the economy and life works for people in the medical field" [Participant 7, liposarcoma]

A website's position in the search engine results was also discussed as an indicator of trustworthiness by four participants, and for three of these participants, it was a consideration in choosing a website. Two participants reported that they perceived websites positioned at the top of the search results list to be advertisements. One of these participants reported that she "could tell by the link" that the website was an advertisement (participant 5, breast cancer). The other said that she felt that the "person paid to have this up here [in first position]" so she would "skip that [link]" (participant
1 , breast cancer). One participant clicked through to the first search result, saying that she "usually" uses this approach when searching for cancer information (participant 3, breast cancer), while another scrolled down the first page of results saying that, although her chosen source was "the tenth one down," she "[did not] care" that she had to scroll down to find her chosen source, because she perceived it to be trustworthy (participant 7, liposarcoma).

\section{Patient-centered source}

Participants $(n=3)$ also reported that the patient-centeredness of their chosen website determined their interest in exploring the website in more depth. In particular, these participants reported that they preferred sources that were specific to their cancer type or reflective of their experiences with cancer or cancer treatment.

\section{Sentiments about information found in searches}

\section{Search result and website navigation}

Half of participants reported that they felt their chosen websites required an excessive amount of navigation to find relevant information $(n=5)$. Three of these participants reported that they had to make multiple searches, either on Google or the website of their choice, to find their desired information. Three reported feeling as if they had to make too many "clicks" to find desired information, both during the task and during their online searches at home. Two of the participants that mentioned frustration about clicks said that two to three clicks were the maximum number of clicks that they would endure during the task to find the information. Three participants also said that they would leave the website if there was too much navigation required to find their desired information. One participant expressed her preferences for website navigation:

"If I can't find the information I'm looking for in probably three clicks, then I'm gonna go on to another website, because there's so many out there. I know I'll be able to find information I want. Why do I need to sit here and spend a half hour on one website just trying to locate something?" [Participant 1, breast cancer]

\section{Recency of information}

Another common sentiment expressed was a preference for the most up-to-date cancer information possible $(n=3$ participants), and these participants specifically searched for publication dates of their chosen website or a content page. These participants reported that information that was published within one to 2 years of their search was acceptable, 
but one said that she would disregard information that was published more than 5 years ago.

\section{Volume of search results}

Three participants also reported that their searches yielded too high a volume of information. One participant expressed frustration with the volume of available sources and the time-consuming nature of choosing a source:

"There was only...three sources that I would use from [the search engine results]...I have gone through two pages and of course there's a billion, right? But...just two of them sound reliable enough to even take the time to go through." [Participant 7, liposarcoma]

\section{Search results and cancer-related anxiety}

Two participants also reported that the information they found either elicited ( $n=1$ participant) or reduced ( $n=1$ participant) anxieties surrounding their cancer experiences. One participant expressed anxiety upon encountering information about the risk of second cancers, reporting that this information confirmed information given to him by his health care provider (participant 10, stomach cancer). The other participant said that if she were able to find information about her own "cancer scenarios," it would help her "calm down a bit" (participant 6 , breast cancer).

\section{Sentiments about aesthetics and features of chosen websites}

\section{Website aesthetics}

Participants reported that they preferred websites that had the following aesthetic characteristics: (1) colorful text that was larger and bolded when demarcating different information sections ( $\mathrm{n}=4$ participants reported this preference); (2) text portions of the website that were not too long, were easily readable, and were separated by bullet points $(n=3) ;(3)$ colorful and "friendly" website designs $(\mathrm{n}=3)$, and websites that contained pictures that depicted relevant cancer information (e.g., what to expect at each stage, pictures of treatments), with a preference for large, bright pictures $(n=4)$. For example, one participant described her experience with the readability and fonts of her chosen website:

"The title appears big so you know once you've finished [a section]. It's telling you what the treatment is and there's stage three so you know to decipher the difference [between information for each cancer stage]... Some important words...stand out in blue, and they're telling you with the bullets what that means...I'm not just reading, reading, reading like a big ol' newspaper arti- cle. They picked out certain things...they made 'em bold and then you read after that." [Participant 3, breast cancer]

Another participant expressed positive feelings towards a picture on her chosen website, saying:

"The picture [of a smiling breast cancer researcher in a lab]...was nice and bright. It wasn't like a 'oh, cancer! Doomsday! You're gonna die!' thing. It kinda made you feel hopeful." [Participant 6, breast cancer]

Finally, one participant said that website aesthetics factored into her perceptions about the organization's credibility (participant 7, liposarcoma).

\section{Website usability features}

Five participants mentioned notable features of their chosen websites that they perceived to be useful. The most commonly mentioned features were live chat capability $(n=2)$ or the option to subscribe to updates/newsletters from the organization $(n=2)$. Other notable features mentioned were having an integrated search bar on the website $(n=1)$, having an integrated printing capability on the website $(n=1)$, having the organization's contact information available on the website $(\mathrm{n}=1)$, and having a blog or forum on the website $(\mathrm{n}=1)$.

\section{Planned actions to take with search information}

Four participants expressed interest in sharing the information found during the search tasks with friends, family, or other cancer survivors. Moreover, three participants said that they would share the search information with their health care provider to help them to evaluate the trustworthiness of the information. One participant described how she might share the search information with her health care provider:

"Would I trust it [information found during search task]? I probably would, but I always get a second opinion. So, I might read this [website] but then I go to my doctor and ask him some questions. That's what I do. Like I write some questions on a paper, and then, when I go to my next visit, I ask him questions um pertaining to what I read on the internet and compare to see if it's true" [Participant $\mathbf{4}$, lung and brain cancer]

\section{Discussion}

This study involved an intensive exploration of online cancer information seeking behaviors and preferences among a small sample of cancer survivors using a participant-guided 
internet search task. Participants reportedly preferred to search for information about their specific cancer type, rather than general cancer information, seeking personalized information about treatments, prognosis, and risk factors. Participants relied on three major sources for cancer information during the search task: non-profit, government, and cancer center/health care/hospital websites. Participants reported that perceived trustworthiness was the main influence on their website choices. They also reported that they had to engage in an excessive amount of navigation to find their cancer information of interest. Participants expressed that aesthetic and usability characteristics of their chosen websites influenced their perceptions about the website and experiences searching. Finally, participants reported that they would consider sharing the information from the search task with friends and family or their health care provider.

Participants most commonly searched for information specific to their cancer, rather than general cancer information, which was reflected in a study analyzing a nationally representative sample in the Health Information National Trends Survey [29]. In particular, many participants were concerned about what to expect during their cancer journey, including side effects of cancer treatment, which has been reflected in other studies of cancer survivors' informational needs $[18,30]$. Participants also commonly searched for available treatments, which presents opportunities for survivors to leverage this information to more actively engage in their treatment plans [17].

Examining the types of sources to which participants navigated is an important contribution, as most online health information seekers cannot accurately recall the websites they use as information sources [20,31], and prior studies of information search tasks have not often reported source types chosen by participants [22, 24]. Exploring cancer survivors' preferred online information sources can help to foster a better understanding the nature of survivors' beliefs and perceptions about cancer and potentially identify sources of misinformation. Participants primarily visited non-profit, government, and cancer center/health care/hospital websites. Several participants also began browsing the search engine results and selecting websites using the Google "people also ask" function. Search engine algorithms are often not transparent, and the search results users encounter are a combination of users' desired search information, the search terms used, and where a website appears on the search engine results page [32]. Search engines are owned by private businesses who profit from advertising revenue and selling keywords to advertisers. Therefore, websites represented in the "people also ask" box may represent not only the content of users' searches but also websites paying to be included in the "people also ask" box, rather than the most evidence-based content [32]. This is concerning because people who utilize the "people also ask" function are less likely to extend their searches beyond the "people also ask" section and may spend less time examining other websites on the search engine results page [33].

Almost all participants reported that the perceived trustworthiness of a website influenced their navigation choices during the search task, which has also been found in other health information seeking studies [22, 34, 35]. This included organizations that were familiar to the participants and for which the informational pages had references to scientific research. Some participants reported being distrustful of organizations that were perceived to have commercial interests, and by extension, pages that contained advertisements. This skepticism was also mentioned in reference to the website's search engine results position, with some participants reporting that search position was purchased, rather than earned through credibility [24]. Participant concerns about commercial interests and advertising may have also contributed to the preference for non-profit websites. Unlike information in peer-reviewed scientific journals, there is markedly less oversight of information quality of online content [36]. As a result, online cancer resources must be evaluated by users on a case-by-case basis, which can be time-consuming and may require skills that exceed the capacity of some health information seekers [37, 38].

Many participants reported frustration about the amount of navigation needed to find their information of interest [24]. Given participants' desire for information specific to their cancer type, reports of excessive amounts of navigation may have reflected barriers to finding personally relevant cancer information. Cancer survivor populations are heterogeneous, and therefore, websites that feature generalized cancer information and lack efficient ways of accessing information by cancer type may be disregarded due to frustration. Navigation-related frustration and time required to find information of interest may also have had implications for participants' willingness to compare multiple sources to validate information. Frustrations about navigation barriers may also explain the tendency for some participants to use the "people also ask" function to address their search, opting for convenience rather than critical vetting of multiple sources. These frustrations demonstrate a need for cancer resources that are disaggregated by cancer type and can be efficiently accessed so that survivors have more time and cognitive capacity to evaluate the credibility of the information. Of course, given that we used a simulated task, participants may have been less invested in thoroughly vetting information than they may be in real-world searches [24]. Participants also reported that they preferred websites with information that was as current as possible, saying that they may disregard information published prior to the past two to 5 years. Upto-date cancer information is frequently cited by cancer survivors as an unmet health information need [17, 39], 
but the desired recency of information may conflict with the timeline needed to conduct and publish cancer research [40]. Furthermore, many cancer websites do not list the date of last update [41], which may cause cancer survivors to overlook potentially useful resources.

Participants cited various aesthetic and usability characteristics that affected their search experiences. Participants expressed a preference for websites with a colorful design, text formatting that clearly demarcates different information sections, concise informational text portions, and prominent visual aids that depict personally relevant cancer information. They also reported that interactive website features such as live chat capability may enhance the cancer information search experience. The reported aesthetic characteristics align with some of the basic principles of healthrelated web design [42], but some aesthetic preferences for cancer-specific resources may be related to the desire to more easily find personally relevant cancer information rather than generalized or other non-relevant information. Furthermore, participants' frustration with the time required to find their information of interest could be partially related to aesthetic and usability aspects of the website. In other words, websites designed in a manner that is not user-centered (e.g., websites that are cluttered, do not use colors or space to highlight important information, and have several sub-menus that require excessive clicks to access information) may take longer to navigate and induce frustration. Websites with streamlined navigation and information sections that are approachable from an aesthetic and usability standpoint can be useful when cancer survivors are receiving distressing medical information and desire expedient access to personally relevant cancer information. These findings may be used to inform survivor-centered design of cancer information websites to better meet users' needs.

Many participants reported that they would share the information found during the search task with friends, family, and other cancer survivors for educational purposes. Some participants also reported that they would share the information with their health care provider to assess the credibility of the information. The reported willingness to share information with providers presents opportunities for providers to discuss online information with cancer survivors, correct misinformation, and direct them to trustworthy sources for cancer information. Given the decreased capacity of providers to manage health information needs throughout cancer survivorship [4], discussing this information early in survivors' health care encounters may promote more informed future searches. Relatedly, given that many participants visited websites affiliated with health care facilities, web developers from health care institutions may consider collaborating with health care providers to ensure that information featured on the institution's website addresses patients' needs.

\section{Limitations}

Despite this study's contributions, some limitations must be considered. First, the sample size was small and may not generalize to a wider sample of cancer survivors. However, we were able to reach saturation of themes with this sample size and ascertain detailed accounts of online information seeking through the intensive nature of the search task. Additionally, study participants were recruited from a limited geographic area and may not be representative of the wider US population of cancer survivors. There was also an overrepresentation of participants who identified as female. Furthermore, although we sought to include participants with a variety of cancer types, $60 \%$ of participants were breast cancer survivors. Our sample was also comprised of survivors who were actively engaged in online information seeking, and many were college educated, which does not reflect the general population of cancer survivors [22]. Participants' computer screens were not recorded during the search task, and the analysis relied on participant narration of their behaviors, rather than objective processing measures (e.g., time on web page or number of clicks), therefore limiting the ability to quantify search behaviors. Finally, although anonymity is one of the advantages of seeking health information online, participants were observed during the task, and their behaviors during the task may have differed from their routine search behaviors [23].

\section{Conclusion}

Cancer survivors, who are routinely exposed to life changing and complex medical information, are becoming increasingly responsible for managing their health information needs outside of health care settings. Survivors' online health information needs require streamlined cancer information resources that are targeted to their cancer type, stage, and treatment course and located on websites with aesthetic and usability features that facilitate expedient searches for personally relevant cancer information. Trustworthiness and recentness of information, as well as perceptions that a website is informational rather than intended for commercial purposes, may also be determinants of cancer survivors' resource selection. These findings suggest opportunities for clinicians to discuss online cancer information with survivors during clinical encounters to ensure that they are accessing evidence-based cancer information online. Further research is necessary to expand these results to broader populations of heterogeneous cancer survivors in order to optimize existing online cancer resources and inform the development of new resources. 
Acknowledgements The authors would like to thank Dr. Richard Moser for his support in coordinating this project, as well as Anita Ousley and the rest of the staff in the NCI Human Systems Integration Lab. We also thank the NCI Division of Cancer Control and Population Sciences for providing the opportunity to pursue this project. We would also like to thank our participants for contributing to the study.

Authors' contributions $\mathrm{AB}$ - conceptualization, interviewing, content analysis, writing main draft.

AS- conceptualization, interviewing, content analysis, contributed to writing/editing

WK- conceptualization, project supervisor, contributed to writing/ editing

\section{Declarations}

Ethics approval This study was approved by the National Institutes of Health Institutional Review Board.

Consent to participate.

Participants provided verbal consent by phone.

Consent for publication.

There are no data or images used that belong to another individual.

Conflict of interest The authors declare no competing interests.

Disclaimer The opinions expressed by the authors are their own and this material should not be interpreted as representing the official viewpoint of the US Department of Health and Human Services, the National Institutes of Health, or the National Cancer Institute.

\section{References}

1. National Cancer Institute. NCI Dictionaries 2020:1. https://www. cancer.gov/publications/dictionaries/cancer-terms/def/survivor (accessed October 8, 2020).

2. Aziz NM, Rowland JH. Trends and advances in cancer survivorship research: challenge and opportunity. Semin Radiat Oncol. 2003;13:248-66. https://doi.org/10.1016/S1053-4296(03) 00024-9.

3. American Cancer Society. Cancer Treatment \& Survivorship Facts \& Figures 2019-2021. Atlanta: American Cancer Society; 2019. https://www.cancer.org/content/dam/cancer-org/research/cancerfacts-and-statistics/cancer-treatment-and-survivorship-facts-andfigures/cancer-treatmentand-survivorship-facts-and-figures-20192021.pdf.

4. Yabroff KR, Lund J, Kepka D, Mariotto A. Economic burden of cancer in the United States: estimates, projections, and future research. Cancer Epidemiol Biomarkers Prev. 2011. https://doi. org/10.1158/1055-9965.EPI-11-0650.

5. Groen WG, Kuijpers W, Oldenburg HSA, Wouters MWJM, Aaronson NK, Van Harten WH. Empowerment of cancer survivors through information technology: an integrative review. J Med Internet Res. 2015. https://doi.org/10.2196/jmir.4818.

6. De Moor JS, Mariotto AB, Parry C, Alfano CM, Padgett L, Kent $\mathrm{EE}$, et al. Cancer survivors in the united states: prevalence across the survivorship trajectory and implications for care. Cancer Epidemiol Biomarkers Prev. 2013;22:561-70. https://doi.org/10. 1158/1055-9965.EPI-12-1356.

7. Shea-Budgell MA, Kostaras X, Myhill KP, Hagen NA. Information needs and sources of information for patients during cancer follow-up. Curr Oncol. 2014;21:165-73. https://doi.org/10.3747/ co.21.1932.
8. Puts MTE, Papoutsis A, Springall E, Tourangeau AE. A systematic review of unmet needs of newly diagnosed older cancer patients undergoing active cancer treatment. Support Care Cancer. 2012;20:1377-94. https://doi.org/10.1007/s00520-012-1450-7.

9. Faller H, Koch U, Brähler E, Härter M, Keller M, Schulz H, et al. Satisfaction with information and unmet information needs in men and women with cancer. J Cancer Surviv. 2016;10:6270. https://doi.org/10.1007/s11764-015-0451-1.

10. Steginga SK, Occhipinti S, Dunn J, Gardiner RA, Heathcote $\mathrm{P}$, Yaxley J. The supportive care needs of men with prostate cancer (2000). Psychooncology. 2001;10:66-75. https://doi.org/ 10.1002/1099-1611(200101/02)10:1<66::AID-PON493>3.0. $\mathrm{CO} ; 2-\mathrm{Z}$.

11. Halkett GKB, Kristjanson LJ, Lobb E, Little J, Shaw T, Taylor M, et al. Information needs and preferences of women as they proceed through radiotherapy for breast cancer. Patient Educ Couns. 2012;86:396-404. https://doi.org/10.1016/j.pec.2011.05.010.

12. Halbach SM, Ernstmann N, Kowalski C, Pfaff H, Pförtner TK, Wesselmann $\mathrm{S}$, et al. Unmet information needs and limited health literacy in newly diagnosed breast cancer patients over the course of cancer treatment. Patient Educ Couns. 2016;99:1511-8. https:// doi.org/10.1016/j.pec.2016.06.028.

13. Pew Research Center. Mobile Fact Sheet. 2019. https://www. pewresearch.org/internet/fact-sheet/mobile/. Accessed 14 Jan 2021.

14. Finney Rutten LJ, Blake KD, Greenberg-Worisek AJ, Allen SV, Moser RP, Hesse BW. Online health information seeking among US adults: measuring progress toward a healthy people 2020 objective. Public Health Rep. 2019;134:617-25. https://doi.org/ 10.1177/0033354919874074.

15. Hesse B, Moser R, Finney Rutten L, Kreps G. The health information national trends survey: research from the baseline. J Health Commun. 2006;11:vii-xvi.

16. Knijnenburg SL, Kremer LC, Van Den Bos C, Braam KI, Jaspers MWM. Health information needs of childhood cancer survivors and their family. Pediatr Blood Cancer. 2010;54:123-7. https:// doi.org/10.1002/pbc.22207.

17. Dolce MC. The Internet as a source of health information: experiences of cancer survivors and caregivers with healthcare providers. Oncol Nurs Forum. 2011;38:353-9. https://doi.org/10.1188/ 11.ONF.353-359.

18. Jansen F, van Uden-Kraan CF, van Zwieten V, Witte BI, Verdonck-de Leeuw IM. Cancer survivors' perceived need for supportive care and their attitude towards self-management and eHealth. Support Care Cancer. 2015. https://doi.org/10.1007/ s00520-014-2514-7.

19. Finney Rutten LJ, Agunwamba AA, Wilson P, Chawla N, Vieux $\mathrm{S}$, Blanch-Hartigan D, et al. Cancer-related information seeking among cancer survivors: trends over a decade (2003-2013). J Cancer Educ. 2016;31:348-57. https://doi.org/10.1007/ s13187-015-0802-7.

20. Rider T, Malik M, Chevassut T. Haematology patients and the internet - the use of on-line health information and the impact on the patient-doctor relationship. Patient Educ Couns. 2014. https:// doi.org/10.1016/j.pec.2014.06.018.

21. Jansen F, van Uden-Kraan CF, van Zwieten V, Witte BI, Verdonck-de Leeuw IM. Cancer survivors' perceived need for supportive care and their attitude towards self-management and eHealth. Support Care Cancer. 2015;23:1679-88. https://doi.org/ 10.1007/s00520-014-2514-7.

22. Feufel MA, Stahl SF. What do web-use skill differences imply for online health information searches? J Med Internet Res. 2012;14:1-11. https://doi.org/10.2196/jmir.2051.

23. Quinn S, Bond R, Nugent C. Quantifying health literacy and eHealth literacy using existing instruments and browser-based software for tracking online health information seeking behavior. 
Comput Human Behav. 2017;69:256-67. https://doi.org/10. 1016/j.chb.2016.12.032.

24. Wu WC, Kelly D. Online search stopping behaviors: An investigation of query abandonment and task stopping. Comput Sci. 2014;51(1):1-10. https://doi.org/10.1002/meet.2014.14505 101030.

25. UserWorks. Participant Recruitment. UserWorks 2018:1. http:// www.userworks.com/recruiting.html (accessed November 8, 2020).

26. Ericsson KA, Simon HA. Protocol analysis. Revised. Cambridge, MA: The MIT Press; 1993.

27. Sandelowski M. Whatever happened to qualitative description? Res Nurs Health. 2000;23(4):34-40. https://doi.org/10.1002/1098240x(200008)23:4<334::aid-nur9>3.0.co;2-g.

28. Terry G, Hayfield N, Clarke V, Braun V. Thematic analysis. In: Willig GW, Rogers S, editors. The sage handbook of qualitative research in psychology. Sage. pp. 17-37.

29. Rutten LJF, Squiers L, Hesse B. Cancer-related information seeking: hints from the 2003 Health Information National Trends Survey (HINTS). J Health Commun. 2006;11:147-56. https://doi.org/ 10.1080/10810730600637574.

30. Fletcher C, Flight I, Chapman J, Fennell K, Wilson C. The information needs of adult cancer survivors across the cancer continuum: a scoping review. Patient Educ Couns. 2017;100:383-410. https://doi.org/10.1016/j.pec.2016.10.008.

31. Eysenbach G, Köhler C. How do consumers search for and appraise health information on the world wide web? Qualitative study using focus groups, usability tests, and in-depth interviews. Br Med J. 2002;9:573-7. https://doi.org/10.1136/bmj.324.7337. 573.

32. Hinman L. Esse est indicato in Google: ethical and political issues in search engines. Int Rev Inf Ethics. 2005;3:19-25.

33. Pothirattanachaikul S, Yamamoto T, Yamamoto Y, Yoshikawa M. Analyzing the effects of "people also ask" on search behaviors and beliefs. Proceedings of the 31st ACM Conference on Hypertext and Social Media, HT 2020, 101-110. 2020. https://doi.org/10. $1145 / 3372923.3404786$.

34. Mendes Á, Abreu L, Vilar-Correia MR, Borlido-Santos J. "That should be left to doctors, that's what they are there for!"- exploring the reflexivity and trust of young adults when seeking health information. Health Commun. 2017;32:1076-81. https://doi.org/10.1080/10410236.2016.1199081.

35. Pang PCI, Verspoor K, Chang S, Pearce J. Conceptualising health information seeking behaviours and exploratory search: result of a qualitative study. Health Technol (Berl). 2015;5:1-11. https:// doi.org/10.1007/s12553-015-0096-0.

36. Tonsaker T, Bartlett G, Trpkov C. Health information on the internet: gold mine or minefield? Can Fam Physician. 2014;60:407-8.

37. Kivits J. Informed patients and the internet: A mediated context for consultations with health professionals. J Health Psychol. 2006;11:269-82. https://doi.org/10.1177/1359105306061186.

38. Stavri PZ, Freeman DJ, Burroughs CM. Perception of quality and trustworthiness of Internet resources by personal health information seekers. Washington, DC: AMIA Annu. Symp. Proc; 2003. p. 629-33.

39. Willems RA, Bolman CAW, Mesters I, Kanera IM, Beaulen AAJM, Lechner L. Cancer survivors in the first year after treatment: the prevalence and correlates of unmet needs in different domains. Psychooncology. 2016. https://doi.org/10.1002/pon. 3870.

40. Prasad V, Mailankody S. Research and development spending to bring a single cancer drug to market and revenues after approval. JAMA Intern Med. 2017;177:1569-75. https://doi.org/10.1001/ jamainternmed.2017.3601.

41. Kobes K, Harris IB, Regehr G, Tekian A, Ingledew PA. Malignant websites? Analyzing the quality of prostate cancer education web resources. Can Urol Assoc J. 2018;12:344-50. https://doi.org/10. 5489/cuaj.5084.

42. U.S. Department of Health and Human Services. Usability.govvisual design basics. US Dep Heal Hum Serv 2013. https://www. usability.gov/what-and-why/visual-design.html (accessed October 9, 2020)

Publisher's note Springer Nature remains neutral with regard to jurisdictional claims in published maps and institutional affiliations. 